\title{
Dimensional accuracy of internal cooling channel made by selective laser melting (SLM) And direct metal laser sintering (DMLS) processes in fabrication of internally cooled cutting tools
}

\author{
S. A. C. Ghani ${ }^{1, *}$, M. H. Zakaria ${ }^{1}, W . S . W$. Harun ${ }^{1}$, Z. Zaulkafilai ${ }^{1}$ \\ ${ }^{1}$ Human Engineering Group, Faculty of Mechanical Engineering, \\ Universiti Malaysia Pahang, 26600 Pekan Pahang, Malaysia.
}

\begin{abstract}
Selective laser melting(SLM) and direct metal laser sintering(DMLS) are preferred additive manufacturing processes in producing complex physical products directly from CAD computer data, nowadays. The advancement of additive manufacturing promotes the design of internally cooled cutting tool for effectively used in removing generated heat in metal machining. Despite the utilisation of SLM and DMLS in a fabrication of internally cooled cutting tool, the level of accuracy of the parts produced remains uncertain. This paper aims at comparing the dimensional accuracy of SLM and DMLS in machining internally cooled cutting tool with a special focus on geometrical dimensions such as hole diameter. The surface roughness produced by the two processes are measured with contact perthometer. To achieve the objectives, geometrical dimensions of identical tool holders for internally cooled cutting tools fabricated by SLM and DMLS have been determined by using digital vernier calliper and various magnification of a portable microscope. In the current study, comparing internally cooled cutting tools made of SLM and DMLS showed that generally the higher degree of accuracy could be obtained with DMLS process. However, the observed differences in surface roughness between SLM and DMLS in this study were not significant. The most obvious finding to emerge from this study is that the additive manufacturing processes selected for fabricating the tool holders for internally cooled cutting tool in this research are capable of producing the desired internal channel shape of internally cooled cutting tool.
\end{abstract}

\section{Introduction}

The temperature distribution at the tool-chip interface of a cutting tool has been a subject of investigation for many years due to resultant workpiece quality and prediction of tool wear $[1,2]$. The conventional method, which is often called flood cooling, is using dousing

* Corresponding author: anwarcg@ump.edu.my 
a large quantity of cutting fluid, usually a mixture of oil and water, to the area in the vicinity of the tool-chip contact region. However, cutting fluid or also addressed as metal working fluid (MWF) in several kinds of literature has been reported to have various adverse effects when in use abundantly [3]. Many cooling fluids contain harmful or damaging chemical constituents causing environment pollution and operator's health hazards, so strict environmental policies and health regulations have been introduced in connection with the increasing awareness of the environment and human health [4]. Based on the report by Canter [5] in 1999, Metalworking Fluids Standards Advisory Committee (MWFSAC) had recommended that the permissible exposure limit for metal working fluids be $0.5 \mathrm{mg} / \mathrm{m}^{3}$. Therefore, Byrne, Dornfeld [4], Sreejith and Ngoi [6], and Wardle, Minton [7] have suggested that dry cutting, a machining process without the presence of external cutting fluid to be the desirable machining approach for the manufacturing industry for producing components and products, to satisfy both ecological and economical requirements.

A new method of cooling should be introduced though, as the excessive heat generated during machining may cause abrupt tool failure, short tool life or bad surface finish produced $[8,9]$. Recently, there are a study on the new method of cooling which are Minimum Quantity Lubricant (MQL)[10, 11], internal coolant[12, 13], and cryogenic[14, 15]. In order to prevent from using excessive cutting fluid and dry machining, an experimental investigation of MQL as sustainable cooling technique was conduct by Rahim, Ibrahim [16]. The result of their experiment was proven that MQL technique performed better than dry machining.

Sun, Bateman [17] has modified a conventional tool to become an internally cooled smart cutting tool by drilling cooling channels in the tool shank and supply the cooling fluid beneath the cutting insert through a special insert support. Through experiment, this method has been demonstrated in that paper to offer great potential for effectively cooling the cutting insert because under the same thermal boundary conditions, the simulated cutting tip temperature and over- all temperature of internally cooled tools are much lower than the non-cooled cutting tools. Other than that, in real cutting situations, a tool with internal cooling can significantly decrease the cutting temperature and thus improve the cutting tool life.

The remaining issue in improving the design of internally cooled cutting tool is that the internally cooled cutting tool cannot be manufactured by using conventional machine due to the complex shape of the cooling channel. Nowadays, rapid prototyping (RP) techniques for metals, also known as metal additive manufacturing (MAM), have gained market share over the recent period, due to improvements in technologies and introduction of new metal powders that are adequate for metal end-products with applications in many fields such as aerospace, dental or medical sectors [18] [19]. Selective Laser Melting (SLM) and direct metal laser sintering (DMLS) are the most common MAM techniques [20]. To date, there are a limited number of works that has been identified which focus on SLM and DMLS part physical performance studies.

Mat Taib, Harun [21] have conducted an experimental investigation on open cellular structure CoCrMo Alloy to analyse the dimensional accuracy of the open cellular structure of CoCrMo samples which consist of unsupported struts (overhang region) fabricated by SLM process. Through the experiment, he found that with the increase in sample porosity leads to increase of shrinkage.

Pessard, Mognol [22] have conducted experimental investigation on complex cast part by using DMLS process to study and verify the geometrical quality of the obtained parts and capability of this process with respect to the required constraints of the die casting method. He found out that the geometrical accuracy of the rapid prototyping machine used in this work is approximately $0.2 \mathrm{~mm}$. This corresponds to a workpiece tolerance of 
approximately $\pm 0.1 \mathrm{~mm}$, with $50 \%$ of this inaccuracy coming from the sintering machine and $50 \%$ coming from the shot-peening.

However, the main drawbacks of SLM and DMLS techniques are its inefficiency to produce high surface quality and dimensional accuracy. In order to have a better understanding on the matter, this study, therefore, aims at analysing the dimensional accuracy of the internally cooled cutting tool fabricated by using SLM and DMLS by comparing the produce to original dimension of CAD drawing.

\section{Methodology}

\subsection{Part design of ICCT}

The ICCT constitutes of three (3) different parts which are the shank, the support and internal flow channel. The shank is a part at where the tool holder is clamped on lathe machine. The role of the support is for allowing the cutting inserts to sit on it perfectly during machining and it is vital that the surface and dimensional geometries to have tight tolerances. The major part of ICCT is the internal flow channel where its inlet and outlet can be found on the inner side of the shank. The dimensions of internal channel are sensitive to defect since any deviation to the geometries will affect the flow regime. The modelling process of ICCT was carried out by using a CAD software which all the dimensions were defined clearly in the 3-dimensional (3D) model. Figure 1 depicts the 3D CAD model of ICCT without a cutting insert and a clamp bit that fixes the insert to the tool holder.

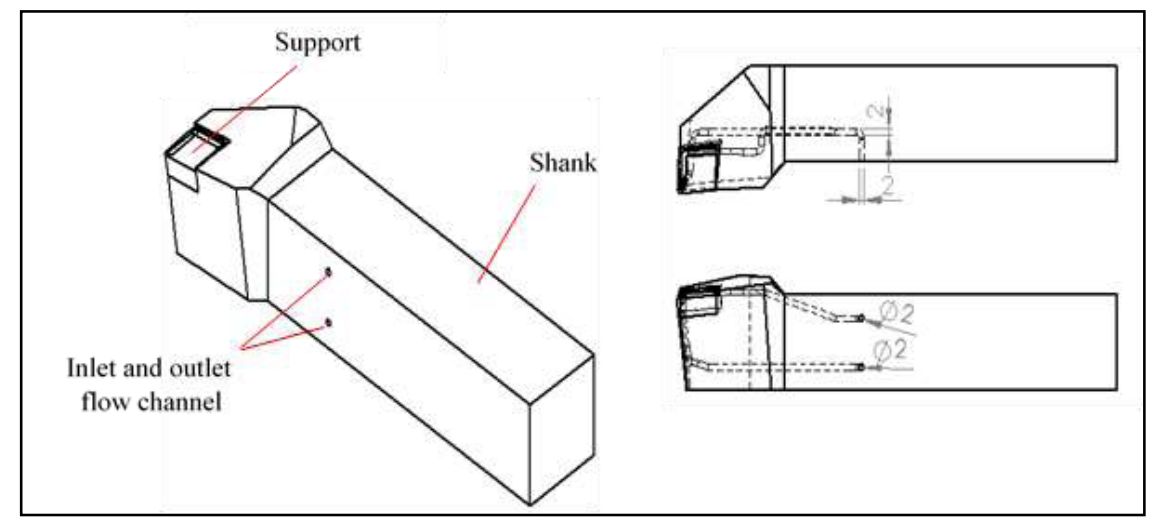

Fig. 1. CAD drawing of ICCT. The units displayed are in $\mathrm{mm}$.

\subsection{Manufacturing of ICCT using SLM process}

The internally cooled cutting tool was fabricated by using SLM machine modelled SLM $280 \mathrm{HL}$. The process started by slicing the 3D CAD file data into layers, usually from 20 to 100 micrometres thick to produce a 2D image of each layer and converted into a .stl file which can be read by most layer-based 3D printing technologies. This file was then loaded into a file preparation software package that assigns parameters, values and physical supports that allow the file to be interpreted and built by different types of additive manufacturing machines. Selective laser melting process commences with selectively melts thin layers of atomised fine metal powder are built onto a substrate plate that is fastened to an indexing table that moves in the vertical $(Z)$ axis as illustrated in Figure 2. This takes 
place inside a chamber containing a tightly controlled atmosphere of inert gas (argon) to prevent oxidation and contamination. Once powder layer has been distributed, each 2D slice of the part geometry is fused by selectively melting the powder. The SLM process parameters in this study are listed in Table 1 . The process is repeated layer after layer until the part is complete.

Table 1. Process parameters of SLM machines.

\begin{tabular}{|c|c|}
\hline Parameters & Value \\
\hline Power $(\mathrm{W})$ & 350 \\
\hline Hatching spacing $(\mathrm{mm})$ & 0.17 \\
\hline Scanning speed $(\mathrm{mm} / \mathrm{s})$ & 930 \\
\hline Layer thickness $(\mu \mathrm{m})$ & 50 \\
\hline Chamber environment & Argon atmosphere \\
\hline
\end{tabular}

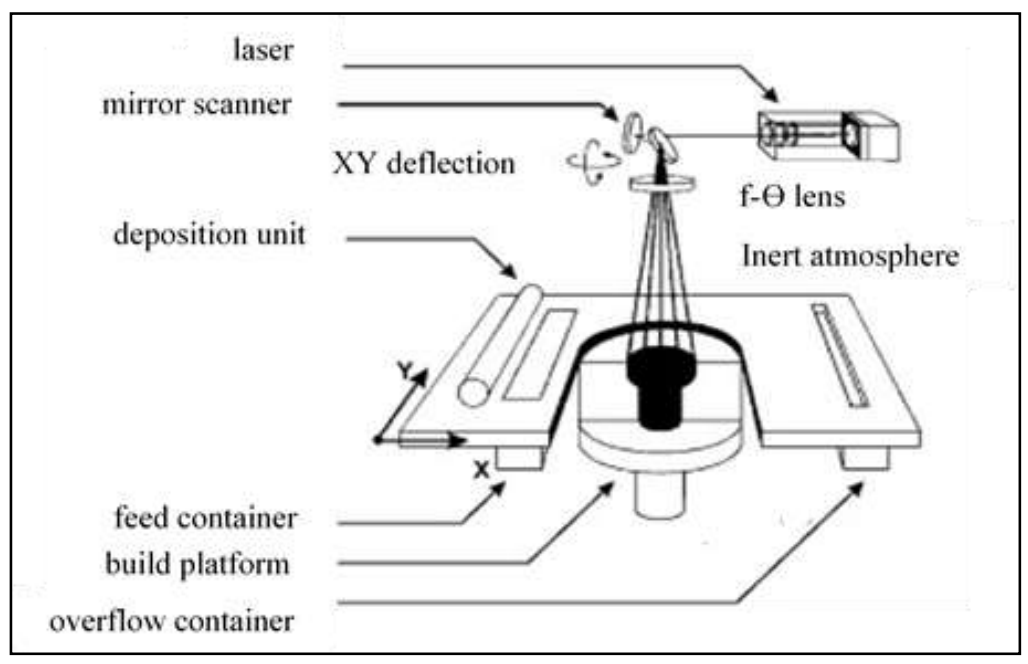

Fig. 2. Illustrated process of SLM.

\subsection{Manufacturing of ICCT using DMLS process}

The internally cooled cutting tool was fabricated by using DMLS machine modelled EOSINT M280. The DMLS process involves the use of a 3D CAD model whereby a .stl file is created and sent to the machine's software. The 3D model will be manually tuned to obtain the optimal orientation of the geometry for part building and supports structures will be added where necessitated. Inside the build chamber area, there is a material dispensing platform and a build platform along with a recoater blade used to move new powder over the build platform. The technology fuses metal powder into a solid part by melting it locally using the focused laser beam. Parts are built up additively layer by layer. Figure 3 show an illustrated working process of DMLS machine. This process allows for highly complex geometries to be created directly from the $3 \mathrm{D}$ CAD data, fully automatically, in a relatively short time and without any tooling. The DMLS process parameters in this study are listed in Table 2. 
Table 2. Process parameters of DMLS machines.

\begin{tabular}{|c|c|}
\hline Parameters & Value \\
\hline Power $(\mathrm{W})$ & 195 \\
\hline Hatching spacing $(\mu \mathrm{m})$ & 0.1 \\
\hline Scanning speed $(\mathrm{mm} / \mathrm{s})$ & 800 \\
\hline Layer thickness $(\mu \mathrm{m})$ & 20 \\
\hline Chamber environment & Nitrogen atmosphere \\
\hline
\end{tabular}

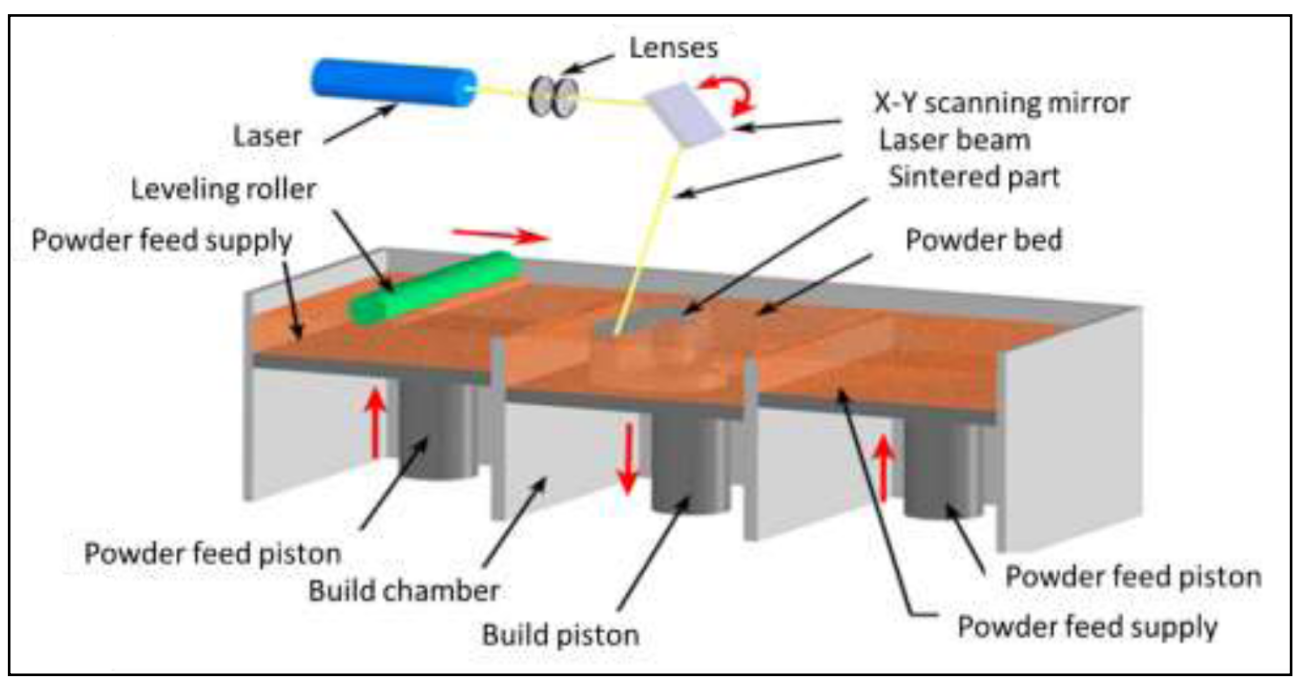

Fig. 3. Illustrated process of DMLS.

\subsection{Measurements}

The measurement was conducted on several sections as listed in Table 3, which is the diameter of inlet and outlet of the channel, diameter of the internal channel at various locations and the arithmetic mean of surface roughness, Ra. Measured dimensional data were then compared to the nominal value as per CAD design for obtaining build error data. In order to determine surface roughness, the MarSurf PS1 perthometer device was used. The geometrical measurement was carried out using Dino-lite edge digital microscope modelled AM4815T and a digital calliper. The features of digital microscope are 1.3MP sensor resolution, adjustable focus and magnification from $20 \mathrm{x}$ up to $220 \mathrm{x}$ and provided with software measurement and calibration.

Table 3. The investigated geometries of an internally cooled cutting tool.

\begin{tabular}{|c|c|c|c|}
\hline Section & Symbol & Unit & Target Value \\
\hline Inlet diameter & $\mathrm{DI}$ & $\mathrm{mm}$ & 2 \\
\hline Outlet diameter & $\mathrm{DO}$ & $\mathrm{mm}$ & 2 \\
\hline Channel diameter & $\mathrm{DC}$ & $\mathrm{mm}$ & 2 \\
\hline Channel surface roughness & $\mathrm{Ra}$ & $\mu \mathrm{m}$ & The lowest \\
\hline
\end{tabular}




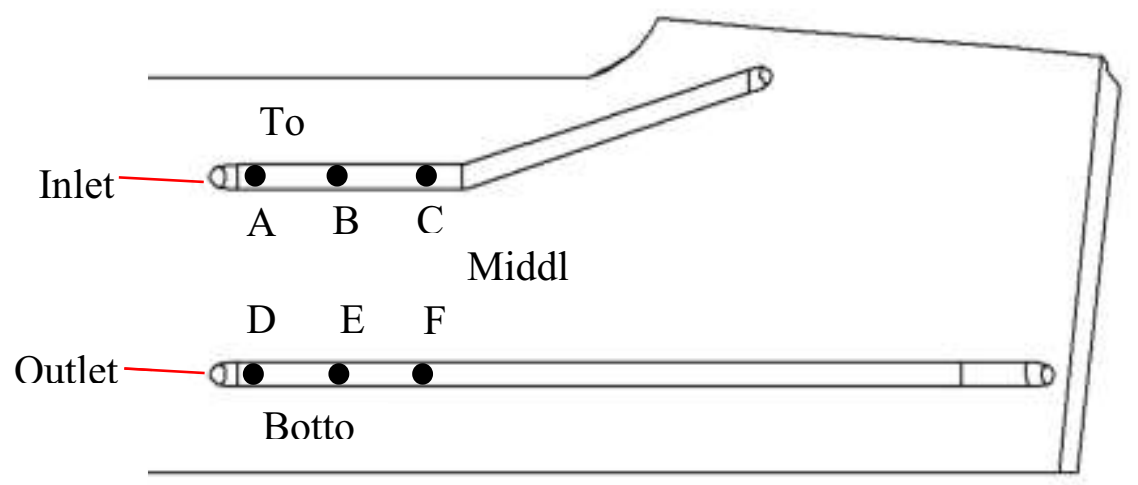

Fig. 4. Half cut CAD drawing ICCT. Black spots in the channel are the points at where the measurements along are taken.

\section{Results and discussion}

Table 4. Measurements of the channel dimension of ICCT.

\begin{tabular}{|c|c|c|c|c|c|c|c|c|}
\hline & & \multirow{2}{*}{ CAD } & \multicolumn{3}{|c|}{ SLM } & \multicolumn{3}{|c|}{ DMLS } \\
\cline { 4 - 9 } & & & $\bar{x}$ & $s$ & Error \% & $\bar{x}$ & $s$ & $\begin{array}{c}\text { Error } \\
\%\end{array}$ \\
\hline & Inlet & 2 & 1.79 & 0.006 & 10.5 & 1.91 & 0 & 4.5 \\
\hline & Outlet & 2 & 1.92 & 0.006 & 4 & 1.92 & 0.006 & 4 \\
\hline \multirow{3}{*}{$\begin{array}{c}\text { Inlet } \\
\text { channel }\end{array}$} & $\mathrm{A}$ & 2 & 1.92 & 0.006 & 4 & 1.99 & 0.012 & 0.5 \\
\cline { 2 - 9 } & $\mathrm{B}$ & 2 & 1.9 & 0.056 & 5 & 1.96 & 0.015 & 2 \\
\cline { 2 - 9 } & $\mathrm{C}$ & 2 & 1.9 & 0.012 & 5 & 2.09 & 0.087 & -4.5 \\
\hline \multirow{3}{*}{$\begin{array}{c}\text { Outlet } \\
\text { channel }\end{array}$} & $\mathrm{D}$ & 2 & 1.93 & 0.035 & 3.5 & 2.02 & 0.053 & -1 \\
\cline { 2 - 9 } & $\mathrm{E}$ & 2 & 1.91 & 0.026 & 4.5 & 2.08 & 0.026 & -4 \\
\cline { 2 - 9 } & $\mathrm{F}$ & 2 & 1.91 & 0.006 & 4.5 & 2.05 & 0.05 & -2.5 \\
\hline & \multicolumn{3}{|c|}{ Mean Value : } & 0.019 & 5.12 & & 0.031 & 2.88 \\
\hline
\end{tabular}

The result of measured dimension of ICCT was shown in Table 4. The standard deviation of ICCT manufactured by using SLM process is $0.019 \%$ which is lower than DMLS process 0.031 . This means the precision of SLM process is better than DMLS. The calculated standard error of the process concealed that the accuracy of DMLS process is higher that SLM process with $2.88 \%$ DMLS and $5.12 \%$ SLM.

Figure 5 shows the graph of surface roughness of ICCT fabricated by using SLM and DMLS process. The surface roughness was measured on 3 different sections as labelled in figure 4. A standard deviation calculated from the data gives 0.383 and 2.01 for each process. The results were revealed that the process of SLM provided better roughness when compared with DMLS process. 


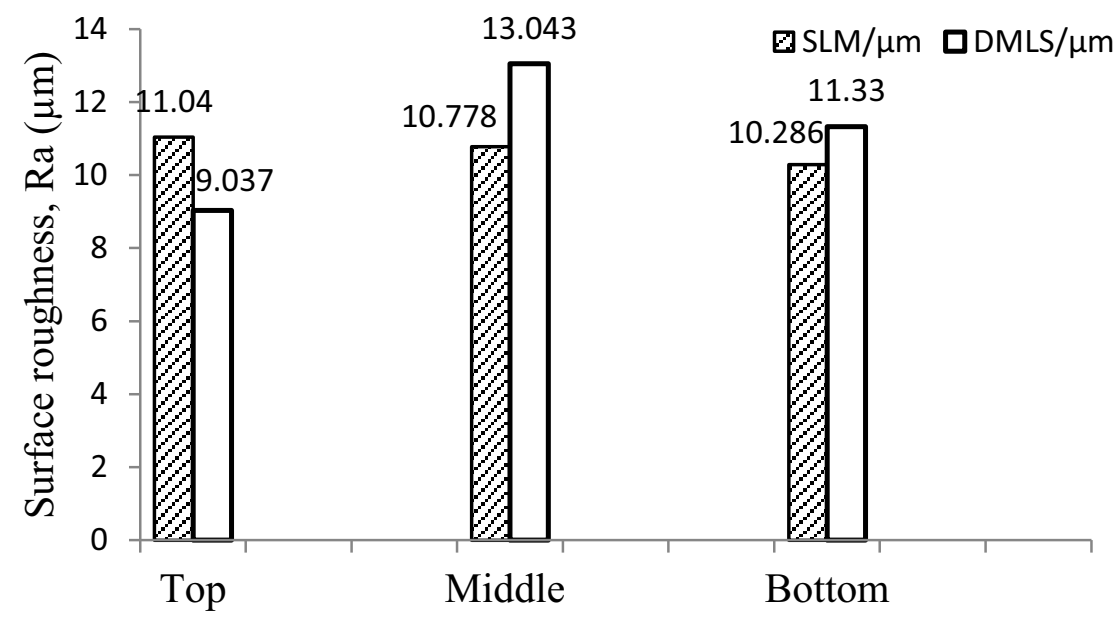

Fig. 5. Comparison surface roughness ICCT of different process.

\section{Conclusion}

This paper discussed a dimensional accuracy of internally cooled cutting tools manufactured by SLM and DMLS process. The following conclusions can be drawn from the present work:

- SLM process provided higher precision than DMLS process.

- DMLS process performed better in dimensional accuracy than SLM process.

- The surface roughness of SLM process is better than DMLS process.

The author would like to thanks to Universiti Malaysia Pahang for providing financial support under project no. RDU 140377 and RDU 150338. The author gratefully acknowledges the committed laboratory support from KKTM(Kuantan) and CONTRAVES SDN. BHD.

\section{References}

1. Usui, E., T. Shirakashi, and T. Kitagawa, Analytical Prediction of Three Dimensional Cutting Process-Part 3: Cutting Temperature and Crater Wear of Carbide Tool. Journal of Engineering for Industry, 1978. 100(2): p. 236-243.

2. Davies, M.A., et al., On The Measurement of Temperature in Material Removal Processes. CIRP Annals - Manufacturing Technology, 2007. 56(2): p. 581-604.

3. Ghani, B.C. and S. Anwar, Design and analysis of the internally cooled smart cutting tools with the applications to adaptive machining. 2013, Brunel University School of Engineering and Design PhD Theses.

4. Byrne, G., D. Dornfeld, and B. Denkena, Advancing cutting technology. CIRP AnnalsManufacturing Technology, 2003. 52(2): p. 483-507.

5. Canter, N., The possibilities and limitations of dry machining. Tribology \& Lubrication Technology, 2009. 65(3): p. 40.

6. Sreejith, P. and B. Ngoi, Dry machining: machining of the future. Journal of materials processing technology, 2000. 101(1): p. 287-291.

7. Wardle, F., et al., Artificial neural networks for controlling the temperature of internally cooled turning tools. 2013. 
8. Umbrello, D., F. Micari, and I. Jawahir, The effects of cryogenic cooling on surface integrity in hard machining: A comparison with dry machining. CIRP AnnalsManufacturing Technology, 2012. 61(1): p. 103-106.

9. Ferri, C., et al., Efficiency in contamination-free machining using microfluidic structures. CIRP Journal of Manufacturing Science and Technology, 2014. 7(2): p. 97105.

10. Dureja, J.S., et al., Performance evaluation of coated carbide tool in machining of stainless steel (AISI 202) under minimum quantity lubrication (MQL). International Journal of Precision Engineering and Manufacturing-Green Technology, 2015. 2(2): p. 123-129.

11. Obikawa, T., 11.11 - Machining with Least Quantity Lubrication A2 - Hashmi, Saleem, in Comprehensive Materials Processing, G.F. Batalha, C.J.V. Tyne, and B. Yilbas, Editors. 2014, Elsevier: Oxford. p. 255-281.

12. Minton, T., et al., Temperature of internally-cooled diamond-coated tools for drycutting titanium. International Journal of Machine Tools and Manufacture, 2013. 75: p. 27-35.

13. Shu, S., et al., An Innovative Method to Measure the Cutting Temperature in Process by Using an Internally Cooled Smart Cutting Tool. Journal of Manufacturing Science and Engineering, 2013. 135(6): p. 061018.

14. Bermingham, M., et al., New observations on tool life, cutting forces and chip morphology in cryogenic machining Ti-6Al-4V. International Journal of Machine Tools and Manufacture, 2011. 51(6): p. 500-511.

15. Machai, C. and D. Biermann, Machining of $\beta$-titanium-alloy $\mathrm{Ti}-10 \mathrm{~V}-2 \mathrm{Fe}-3 \mathrm{Al}$ under cryogenic conditions: Cooling with carbon dioxide snow. Journal of Materials Processing Technology, 2011. 211(6): p. 1175-1183.

16. Rahim, E., et al., Experimental investigation of minimum quantity lubrication (MQL) as a sustainable cooling technique. Procedia CIRP, 2015. 26: p. 351-354.

17. Sun, X., et al., Design and analysis of an internally cooled smart cutting tool for dry cutting. Proceedings of the Institution of Mechanical Engineers, Part B: Journal of Engineering Manufacture, 2012. 226(4): p. 585-591.

18. Giannatsis, J. and V. Dedoussis, Additive fabrication technologies applied to medicine and health care: a review. The International Journal of Advanced Manufacturing Technology, 2009. 40(1-2): p. 116-127.

19. Melchels, F.P.W., et al., Additive manufacturing of tissues and organs. Progress in Polymer Science, 2012. 37(8): p. 1079-1104.

20. Murr, L.E., et al., Metal fabrication by additive manufacturing using laser and electron beam melting technologies. Journal of Materials Science \& Technology, 2012. 28(1): p. 1-14.

21. Mat Taib, Z.A., et al. Dimensional Accuracy Study of Open Cellular Structure CoCrMo Alloy Fabricated by Selective Laser Melting Process. in Advanced Materials Research. 2016. Trans Tech Publ.

22. Pessard, E., et al., Complex cast parts with rapid tooling: rapid manufacturing point of view. The International Journal of Advanced Manufacturing Technology, 2008. 39(910): p. 898-904. 